\title{
Refinement and Drawing Lessons from Traditional Chinese Cultural Elements for Cultural and Creative Product Design
}

\begin{abstract}
Yufen Li*
Department of Creative and Design, Guangzhou Huashang College, Guangzhou 511300, Guangdong Province, China

*Corresponding author: Yufen Li, sougua519919@163.com

Abstract: Chinese culture has been continuously developing for 5000 years of historical development. Its traditional culture has had an impact on social development, and this traditional culture is rooted in the development of the society. The traditional Chinese culture also has certain significance for the design of modern cultural and creative works, which does not only inject vitality for cultural and creative products, but it also enhances the artistry of cultural and creative products. Therefore, based on this, this paper expounds the concept of traditional Chinese culture with cultural and creative products, analyzes the value of traditional culture in cultural and creative products, and explores how to refine and draw lessons from traditional Chinese cultural elements in the process of cultural and creative product design.
\end{abstract}

Keywords: Cultural and creative products; Product design; Traditional Chinese cultural elements; Refinement and drawing lessons

Publication date: August 2021; Online publication: August 30, 2021

\section{Introduction}

The process of cultural and creative design is to achieve the organic integration of culture and art to produce new works of art. For cultural and creative design, there is a need to integrate different cultural forms and works on the basis of cultural development and drawing lessons so that it can be formed on a specific carrier. This process is a collision of human wisdom and a combination of art forms. In the process of cultural and creative product design, there is a need to lay the foundation in time to ensure that all resources can play their maximum roles and enhance their values. For designers, they need to constantly use their creative ability to achieve the recreation of cultural works.

\section{Traditional culture with cultural and creative product design}

The forms of traditional Chinese culture are diverse in the process of the continuous development of Chinese history where various elements contained in the traditional Chinese culture have their own unique value $^{[1]}$. The main forms of traditional Chinese culture are found in clothing, porcelain, food, calligraphy, embroidery, and so on. At the same time, cultural forms vary across different regions. For example, in terms of embroidery, Inner Mongolia have more patterns with fighting animals, fishes, and birds, while in Xinjiang region, the patterns found are more of flowers and birds. In addition, the same cultural form would change for different purposes. For example, in terms of jades, different forms and characteristics of works may be produced in view of different jade qualities. Along with historical development, various traditional cultures do not only have various historical forms, but they also have great vitality, which could have a great impact on people's aesthetic views. 
The designing of cultural and creative works are divided into school supplies, souvenirs, daily necessities, and so on ${ }^{[2]}$. The current design of cultural and creative works is affected by modern cultural elements, and it develops toward a more diversified trend which shows the characteristic of diversification. Therefore, when designing cultural and creative works, designers can integrate diversified art forms into this process to form an organic combination across cultures. In regard to traditional culture, China's cultural heritage and cultural forms are diverse which is of great significance for the realization of cultural forms to enrich designers' ideas. At the same time, it can also motivate designers to form a catalyst for problems.

\section{Value of traditional culture in cultural and creative products}

Firstly, it arouses the recognition of consumers. With the continuous development of various information technology in the current society, people's ideology is becoming diversified. Therefore, it is hard to unify people's thinking. People are eager to find elements or different thoughts that resonate with their own ideology. The integration of traditional cultural elements into cultural and creative works allows the integration of the traditional Chinese idea of unity between man and nature, as well as the improvement in the artistic conception of works. The creation of this artistic conception can arouse resonance in more people and realize the guidance of their understanding of the world. Secondly, it enhances cultural self-confidence. The self-confidence of Chinese culture is actually the recognition of Chinese culture and its cultural forms. Cultural recognition can promote people to form three correct outlooks and realize the recognition of the spiritual world. All kinds of cultural forms in traditional culture are able to carve a brand in people's body and provide more spiritual power which is a factor that has a great impact on China's economic development. Thirdly, it enhances the value of cultural and creative products. Cultural and creative products have a certain added value when they are applied where they have an impact on people's spirits. Various elements in traditional culture have certain impact. For example, paintings contain the power to purify people's spirits, which allows people to have richer artistic enjoyment. This added value even exceeds the value of cultural and creative products.

\section{Refinement and drawing lessons from traditional Chinese cultural elements for cultural and creative product design}

\subsection{Rational use of graphic elements}

Elements of different times have different characteristics in China's historical development where they may have different effects on cultural and creative design. In the current design process of cultural and creative works, one may combine the patterns in cultural and creative works with traditional cultural elements to realize the collision of the traditional and modern concepts. For example, when designing daily necessities, designers often use triangles which improves the three-dimensional sense and artistry of cultural and creative works. Hence, designers can apply typical traditional historical patterns, such as clouds and lightnings to their designs. In this way, designers would be able to combine traditional cultural forms with modern design concepts to create more cultural and creative works with Chinese characteristics.

\subsection{Creation of rich artistic conception}

Traditional Chinese culture is intangible with the embodiment of the spirit in the development of the Chinese history. Traditional Chinese culture can be displayed with the help of various cultural carriers which provide inspirations for the design of cultural and creative works. In this process, designers can integrate the artistic conception of traditional culture into cultural and creative works so that the audience may understand the contained connotations in the process of appreciating cultural and creative works. In 
the creation of modern cultural and creative works, creators need to accurately grasp the overall artistic tone of the works, rationally choose traditional Chinese culture, as well as integrate their forms and meanings to display the connotations. Designers can also elaborate on traditional culture through cultural and creative works to realize the collision between the old and new. For example, designers can use landscapes and characters in watercolor paintings as their themes to display the humanistic spirit and art forms in cultural and creative works. While designing, there is a need to consider the cultural level and artistic accomplishment of the audience in addition to understand their acceptance of traditional culture. Then, recreating on this basis, the cultural and creative works would be more accorded with the reality of the audience.

\subsection{Ingenious transformation of cultural implication}

Traditional culture has its own unique cultural implication in the development process. In designing modern cultural and creative works, there is a need to deeply interpret the implication contained in traditional culture, and according to its connotation, one should match the overall color of the product and select the required materials. In this way, it is possible to create more high-quality literary works and achieve the use of cultural and creative works to stir people's emotions. Therefore, designers need to pay attention to the main features contained in traditional culture to portray them through cultural and creative works so as to achieve more effective display of traditional culture and reflect the artistic conception contained in it.

\subsection{Product design by means of narration}

Narrative cultural creation is extremely necessary for cultural works in which it allows the audience to appreciate the emotion and story contained in the cultural works. Therefore, designers also need to integrate the cultural stories contained in traditional culture into cultural and creative products in order to obtain the resonance of more viewers. The elements of traditional culture have a certain visibility; hence, designers should display traditional culture more vividly in front of the audience so as to enhance the value of a work

${ }^{[3]}$. Designers can convey the story of traditional culture to the audience through cultural and creative works. In this way, cultural and creative works are regarded as the carriers of culture, and the organic combination of traditional culture with cultural and creative works can be realized. For example, when designing cultural and creative products, red culture can be integrated. When designers introduce red culture, they would be able to take into consideration of the needs of the consumers and integrate the glorious deeds of the $100^{\text {th }}$ anniversary of the Chinese Communist Party into cultural and creative works. This way would not only satisfy the appreciation in spirit, but also would effectively integrate the red culture into cultural and creative works.

\section{Conclusion}

To sum up, the traditional Chinese culture has a relatively long history. It is an ideological form formed on the basis of the continuous development of China's history, and it has an impact on modern people's ideas. In the process of modern cultural and creative product design, focusing on the integration of traditional cultural elements is a form of guiding the spirits of the modern people, which plays a role in enhancing the artistic value of cultural and creative works. At the same time, cultural and creative works have also become the carrier of traditional culture dissemination; that is, realizing the dissemination of traditional Chinese culture.

\section{Disclosure statement}

The author declares that there is no conflict of interest. 


\section{References}

[1] Yang H, 2020, Refinement and Drawing Lessons of Cultural and Creative Art Product Design for Traditional Cultural Elements in China. Artworks Appreciation, (30): 88-9.

[2] Xiao S, 2019, The Application of Chinese Traditional Elements in the Design of Cultural and Creative Products. Art Appreciation, (21): 298-9.

[3] Wang X, 2020, Research on Innovative Design of Tourism Products Based on Traditional Folk Culture - Review of Cultural Creativity and Tourism Product Design. Water Conservancy and Hydropower Technology, 560(06): 208. 